\section{Reprodução, sexualidade e poder: as lutas e disputas em torno do aborto e da contracepção no Rio de Janeiro, 1890-1930}

Reproduction, sexuality and power: the struggles and disputes over abortion and contraception in Rio de Janeiro, 1890-1930

Marinete dos Santos Silva

Professora/Universidade Estadual do Norte Fluminense Darcy Ribeiro. Av. Alberto Lamego, 2000 28013-602 - Campos dos Goytacazes - RJ - Brasil mdss@uenf.br

Recebido para publicação em agosto de 2010. Aprovado para publicação em abril de 2012.
SILVA, Marinete dos Santos. Reprodução, sexualidade e poder: as lutas e disputas em torno do aborto e da contracepção no Rio de Janeiro, 1890-1930. História, Ciências, Saúde Manguinhos, Rio de Janeiro, v.19, n.4, out.-dez. 2012, p.1241-1254.

\section{Resumo}

Este artigo analisa o debate de médicos acerca do aborto, da virada do século XIX até os anos 1930, sobretudo na Academia Nacional de Medicina. Considerado um crime, o aborto era visto como algo que ameaçava o domínio dos maridos sobre as esposas e o controle dos atos médicos em relação ao corpo feminino. As parteiras, tidas como as divulgadoras das técnicas médicas de interrupção da gravidez, foram combatidas como grave ameaça à ordem de gênero constituída. Foram analisadas dez teses da Faculdade de Medicina do Rio de Janeiro, os boletins da Academia Nacional de Medicina e matérias publicadas nos jornais Correio da Manhã e O Globo.

Palavras-chave: aborto; crime; corpo; parteiras; dominação.

\section{Abstract}

This article examines the debate among physicians over abortion, from the turn of the nineteenth century through to the 1930s, especially in the Academia Nacional de Medicina (National Academy of Medicine). Considered a crime, abortion was seen as something that threatened the dominance of husbands over wives and the control over medical practice in relation to the female body. Midwives, seen as the propagators of the techniques of medical termination of pregnancy, were opposed as a serious threat to the established gender order. Ten theses of the Faculdade de Medicina do Rio de Janeiro were analyzed, as well as the bulletins of the Academia Nacional de Medicina and articles published in the Correio da Manhã and O Globo newspapers.

Keywords: abortion; crime; body; midwives; domination. 
Marinete dos Santos Silva

\begin{abstract}
A prática clandestina do aborto no país leva milhares de mulheres aos hospitais todos os anos e causa prejuízo de milhões ao Estado. Nos últimos cinco anos, 1.205.361 mulheres foram atendidas em hospitais da rede pública, em busca de assistência médica, por terem interrompido a gravidez usando métodos arriscados e sem qualquer segurança. O custo para o Sistema Único de Saúde (SUS) das curetagens realizadas após abortos ilegais chegou a R \$161,4 milhões no período.
\end{abstract}

Os números do Ministério da Saúde revelam que a interrupção voluntária da gravidez indesejada, além de hoje ser crime, é também um grave problema de saúde pública. Os dados oficiais indicam que o aborto é a terceira causa de morte materna. Dos 1.645 óbitos obstétricos ocorridos em 2004, 155 (13\% do total) foram por abortos. Números como esses levaram o Ministro da Saúde, José Gomes Temporão, a comprar briga com a Igreja Católica e propor debate sobre o aborto.

(Aborto..., 20 maio 2007, p.3)

No Rio de Janeiro, as discussões acerca do aborto tomaram corpo na segunda metade do século XIX. Nesse debate, os médicos reunidos em torno da Academia Nacional de Medicina tiveram papel preponderante. A Academia preocupava-se em reproduzir artigos estrangeiros com vistas a atualizar a comunidade médica, e em seu seio, travavam-se debates sobre temas palpitantes que mobilizavam os médicos, das capitais europeias. Nascida já sob o signo da medicina higienista, a criança e principalmente a mulher foram para ela personagens caros. Desde sua formação, temas como a gravidez, o parto, o aborto, o infanticídio, o aleitamento e a mortalidade infantil eram enfocados em memórias e teses escritas por seus membros. Respaldados em sua formação científica e utilizando argumentos de autoridade, os médicos da Academia opinavam sobre tudo que dissesse respeito à mulher, até mesmo sobre moda e vestuário. Seguindo os passos de seus confrades franceses, os doutores brasileiros não mediram esforços no sentido de definir a mulher e de desvendar os 'mistérios' do corpo reprodutor.

A reprodução humana constitui a base das relações de gênero e é justamente através dela que se operam o controle e a apropriação das mulheres. Sua capacidade biológica de gerar crianças sofre escala crescente de manipulações sociais, através das quais se opera a imposição da reprodução. Embora o casamento seja potencialmente o lugar perfeito para a exposição permanente das mulheres à fecundação, há também um aparelho complexo e variável de pressões ideológicas e psíquicas sobre elas para que a função procriadora seja permanentemente atualizada. Os meios colocados em ação com um objetivo reprodutivo têm três momentos específicos: a aprendizagem do coito, a obrigação em relação ao chamado dever conjugal e a vigilância exercida sobre a fecundação, a gravidez e o parto. Canaliza-se, assim, através da socialização, a pulsão sexual das mulheres para um único tipo de sexualidade, ou seja, aquela ligada à reprodução (Tabet, 1985, p.66).

Desde o início da década de 1840, um expressivo número de teses sobre o aborto espontâneo, o aborto terapêutico e o chamado aborto criminoso começou a ser elaborado. 
Embora muitas delas não passassem de meras repetições de trabalhos anteriores, achamos que a insistência em focalizar o assunto aponta para três pontos importantes. O primeiro deles, sem dúvida, é o de que a produção científica da Academia de Medicina acompanhava as discussões travadas nas capitais europeias, sobretudo o que se debatia em sua congênere francesa. Os médicos, autores das teses, referem-se com frequência a elas, citando exaustivamente e com extrema reverência os mestres franceses. O segundo ponto seria uma sensível evolução do foco de interesse. Se, em um primeiro momento, os pontos-chave são as técnicas de interrupção da gravidez - o chamado aborto terapêutico - utilizadas pelos próprios médicos em mulheres cujo estreitamento da pélvis não possibilitaria o parto normal, em um segundo momento, a preocupação passa ser o chamado 'aborto criminoso', ou seja, aquele praticado clandestinamente por parteiras e curiosas ou pelas próprias interessadas. Tanto aborteiras quanto abortadas são consideradas criminosas, a carga maior sendo dirigida contra as primeiras. Uma explicação que nos parece bastante plausível para tanto consiste no fato de que os médicos travavam uma luta política contra as parteiras pelo controle exclusivo dos atos ligados à reprodução. Ao acusá-las de 'aborteiras' sem escrúpulos, de ignorantes e de responsáveis pela morte de gestantes, desacreditavam-nas perante a sociedade e chamavam para si o monopólio da interrupção da gravidez e também dos partos (Mott, 1992).

O terceiro ponto que nos parece de extrema importância na produção científica dos médicos acerca do aborto é a constatação de que ele não era realizado apenas por mulheres solteiras que desejavam esconder sua 'desonra' ou por prostitutas cuja gravidez atrapalharia a venda de seus encantos. Os médicos descobrem na virada do século que o aborto era amplamente empregado como método contraceptivo por mulheres casadas. A constatação desse fato inquietante levou a conjecturas morais e sociais de amplo espectro. A infidelidade conjugal era uma delas. Diante da facilidade com que as mulheres casadas abortavam, quem poderia garantir que por trás desse gesto não estariam o 'lar e a família' sendo 'maculados' pelo adultério feminino? Além disso, as preocupações natalistas visivelmente importadas da França começavam a inquietá-los. ${ }^{1}$ Apesar de as estatísticas oficiais não darem conta de uma baixa da natalidade no Brasil, se especulava a esse respeito, argumentando-se invariavelmente que a extensão territorial do país exigia a produção massiva de crianças que viriam a ocupar os enormes vazios demográficos existentes.

O debate sobre a utilização do aborto como método contraceptivo por mulheres casadas acabou sendo engolfado por outro mais amplo, ligado à limitação dos filhos pelo casal. Tratava-se de um movimento de caráter internacional chamado de neomalthusianismo.

Em 1803, o economista inglês Thomas Robert Malthus lançou seu Ensaio sobre o princípio da população, no qual preconizava a limitação dos nascimentos como única opção eficaz na luta contra a miséria. Pastor anglicano e grande defensor da ordem social, Malthus estava longe de encorajar o aborto ou qualquer outro tipo de intervenção artificial nas relações sexuais dos cônjuges. Para ele, era fundamental submeter 'a carne ao espírito', ou seja, os casamentos deveriam ser tardios, realizando-se somente a partir dos 30 anos de idade. Propunha também o fim das relações extraconjugais e a diminuição dos contatos sexuais entre marido e mulher. O malthusianismo cedeu lugar ao neomalthusianismo, que aproveitou sua ideia básica - a diminuição do número de filhos - mas não seus princípios. 
Contrariamente ao que era propugnado pelo pastor anglicano, os neomalthusianos não achavam que a carne se deveria submeter ao espírito. Era preciso que a contracepção fosse empregada sob todas as suas formas: o coito interrompido, o preservativo, o diafragma vaginal, as lavagens vaginais pós-coito e mesmo o aborto. Essas ideias generalizam-se na França a partir da segunda metade do século XIX (Gleyses, 1994, p.66).

Sua chegada ao Brasil ocorreu no início do século XX e deu ensejo a um grande debate entre os médicos brasileiros acerca da ilegalidade não apenas do aborto, mas de qualquer método 'fraudulento' que pudesse ser utilizado pelos casais no intuito de não gerar filhos. O fato de a relação sexual entre cônjuges ser realizada sem finalidade procriativa era extremamente perturbador. Questionava-se o engajamento da mulher casada em jogos sexuais não próprios à sua condição e mais condizentes com aquelas que se prostituíam. Em sua tese de doutoramento, o médico Luiz Gonzaga Vianna Barbosa (1911, p.118) deixava bem claro seu pensamento a respeito:

Posta de lado a questão da esterilidade desonesta do congresso sexual realizado entre indivíduos não casados, esterilidade que há de existir enquanto existir a prostituição passemos a analisar a esterilização desonesta do congresso sexual entre casados. Com efeito, repugna ver-se como no Brasil, país de riquezas e de trabalho fácil, o homem e a mulher, legitimamente unidos pelo matrimônio, já procuram, à maneira do que se passa em França e em outros países, evitar a todo transe a procriação, e isso única e exclusivamente por motivos de egoísmo e de bem-estar individual! A ideia de filhos, para o casal brasileiro, já passa a ganhar as proporções gigantescas de um terrível pesadelo! E isto não pode continuar assim! O homem e a mulher, antes de se unirem legalmente devem, de antemão, lembrar-se que o fazem, visando tão somente à constituição de uma família, à formação de um lar feliz.

Embora unidos na posição contrária ao aborto não estritamente terapêutico, os médicos discordavam a respeito da utilização de outros meios anticoncepcionais. A primeira década do século XX também foi marcada pela chegada ao Brasil da eugenia, que buscava impor normas que disciplinassem a reprodução da espécie. Enquanto forma inovadora de intervenção da medicina higienista, ela buscava redimensionar a problemática das raças e de suas relações com a realidade social. Segundo as teorias raciais então em voga, o mestiço, resultado do cruzamento de negros, brancos e índios, indivíduo tipicamente brasileiro, representava um problema para o desenvolvimento do país em razão de sua "inferioridade" biológica (Marques, 1994, p.33). Imbuídos dessa ideologia, alguns médicos passaram a pensar na contracepção como forma de diminuir a pobreza - por coincidência, os mais pobres eram os negros e mestiços - e de 'melhorar' a raça. A princípio, de maneira um tanto tímida e pregando a utilização dos anticoncepcionais apenas temporariamente - recusava-se a esterilizarão permanente da mulher através da ovariotomia e da histerectomia - essa medida era recomendada aos casais que passavam por dificuldades econômicas até que pudessem se reequilibrar. O moral restraint aconselhado por Malthus era considerado utópico, uma vez que seria possível "implantar no lar as perversões amorosas, perigos cujas consequências de degradação moral seriam a lamentar" (Mello, 1911, p.39). Além disso, o marido poderia procurar "fora do lar prazeres ilícitos nos braços das mercadejadoras de amor" (p.38) com o risco de contrair a sífilis, que seria prejudicial à sua saúde, à de sua esposa e dos filhos que 
viessem a nascer. Dessa forma, a solução estaria no preservativo, que já era importado pelo Brasil - seu uso destinava-se à prevenção da sífilis - e que só deveria ser utilizado com aconselhamento médico. A reprodução descontrolada dos mais pobres, segundo se pensava, traria problemas graves ao país: "Indivíduos procriados em más condições morais e, mais ainda, não encontrando meios bastantes para serem criados, tornam-se enfezados e, se não morrem, produzirão futuramente outros nas mesmas condições, trazendo por consequência um depauperamento da raça" (Mello, 1911, p.39).

À medida que o discurso eugênico se impunha, algumas teses médicas vieram à luz na defesa da contracepção sob a forma da continência, do uso do preservativo e até mesmo da esterilização feminina (Costa, 1913; Vilhena, 1919; Ligiero, 1930). O aborto, entretanto, continuou condenado à clandestinidade e diabolizado não só pelos médicos.

Em 1911, estourou um grande escândalo na cidade a propósito de um médico italiano que exercia suas atividades profissionais realizando abortos e operações de esterilização. Uma de suas clientes, após ter sido esterilizada, começou a apresentar perturbações mentais e foi internada em um manicômio. Esse fato deu origem a um processo criminal contra o médico e ganhou enorme repercussão junto à imprensa. ${ }^{2}$ Atuando na acusação, o advogado Evaristo de Morais, em artigo publicado em prestigiado periódico, intitulado "Os inimigos do povoamento esterilizadores e abortistas", fazia carga contra o que chamava de "vergonhosa patifaria que atualmente nos degrada no que se relaciona com a função suprema da mulher" (Morais, 1911, p.2). Conforme o conhecidíssimo rábula: "Na mesma tropa se regimentam médicos indignos, parteiras levianas, supostas massagistas, curandeiros e curandeiras, feiticeiros e feiticeiras, falsos espiritistas, toda uma caterva de gananciosos sem escrúpulos, que exploram o vício e a miséria, seguros da impunidade!" (p.2).

Sua ira contra o médico que executara a malsucedida operação de esterilização incluía todos aqueles que realizavam abortos, prática que, segundo ele, já se estendera às "classes proletárias". Evaristo de Morais (1911, p.2) observava que já havia uma "tabela dos proletários" prevista no caso de escassez de recursos dos clientes, com pagamentos em prestações mensais: "O preço de um aborto tem baixado consideravelmente. Outrora não era inferior a um conto de réis, sendo o pagamento à boca do cofre. Agora, suspeitamos, por informações fidedignas, que o trabalho dos legítimos profissionais ainda é mais barato do que o dos curandeiros: por duas dezenas de mil réis se atenta contra o artigo 301 do Código Penal, sem receio da grave penalidade que se prescreve".

É necessário assinalar que as discussões acerca do aborto permearam as três primeiras décadas do século XX, mobilizando amplos setores da sociedade. Em 1918, uma conferência realizada no Instituto da Ordem dos Advogados Brasileiros, deixava transparecer a importância que se atribuía ao assunto. Aludindo ao fato de que a Ordem dos Advogados não poderia se furtar às responsabilidades que tinha em face do problema da repressão ao aborto criminoso, o conferencista chamava a atenção para aquela "relevante questão jurídico-social, cuja importância avulta no momento presente, em que se cuida de fortalecer a nossa nacionalidade" (Silveira, 1918, p.4).

Segundo ele:

Não lhe é lícito [à entidade], por conseguinte, cerrar os lábios ante a propaganda malthusiana, pregada sem receios nem temores, na nossa sociedade; cabe-lhe o indeclinável 
dever, ad instar do que há praticado a Société Générale des Prisons de Paris de estudar os meios que possam estancar esta caudal imensa de males sociais, provocados pelo aborto e consequente propagação de ideias, anúncios e avisos que a moral religiosa repudia e o Direito condena (Silveira, 1918, p.4).

Foi, porém, na Academia Nacional de Medicina que se travou o mais amplo debate sobre a questão. Visivelmente influenciado pelo que então se passava na França, um grupo expressivo de médicos começou a exigir medidas enérgicas dos poderes públicos no sentido de coibir o que eles consideravam uma marcha ascendente do aborto na cidade do Rio de Janeiro. Em sessão da Academia de 25 de abril de 1918, o médico Fernando de Magalhães relatava as experiências por ele vivenciadas com mulheres que o procuravam em seu serviço da maternidade desejando abortar ou mesmo com sequelas gravíssimas, resultantes da indução do aborto realizado por parteiras ou por elas próprias. Tal como Evaristo de Morais alguns anos antes, chocava-se ao constatar que esse tipo de intervenção não estava restrito a mulheres das classes abastadas. Àquela altura, mesmo as mulheres pobres, segundo o médico, procuravam restringir a natalidade porque liam "os anúncios que nesse sentido saem diariamente nos jornais" (Academia Nacional de Medicina, 1918a, p.35).

Ainda nesse mesmo ano, os médicos Ernesto do Nascimento Silva, Carlos Pinto Seidl, Fernando de Magalhães, Afrânio Peixoto e Olímpio da Fonseca apresentaram na sessão do dia 25 de julho uma moção solicitando ao Parlamento da República uma legislação especial para o crime de aborto. O documento sugeria que as novas disposições legais registrassem em sua redação uma série de medidas. Entre elas, figuravam a proibição e a repressão de toda e qualquer propaganda neomalthusiana; a proibição e a repressão de anúncios e quaisquer publicações ou atos favorecendo a prática do aborto; a vigilância ativa e efetiva das chamadas casas de partos (locais dirigidos por curiosas ou parteiras diplomadas nos quais muitas gestantes se recolhiam para dar à luz); a notificação à autoridade sanitária dos casos de mortinatalidade e de aborto como já se realizava de forma compulsória com várias doenças infectocontagiosas; a entrega do julgamento do crime de aborto a um juiz togado e não mais ao tribunal do júri como até aquela data se verificava; a absolvição da abortada que revelasse o nome do abortador; o direito do médico clínico, até então dispensado por lei de dar o seu depoimento perante a justiça, de fazê-lo, depondo em justiça repressiva, sobretudo contra os abortadores; e direito de citação direta, no crime de aborto, às associações médicas, às administrações públicas, a todos os estabelecimentos públicos (Academia Nacional de Medicina, 1918b).

Esse documento, submetido à Academia, gerou enorme polêmica que se arrastou por mais de dois anos. As críticas iam desde a ilegalidade e a ilegitimidade das medidas propostas até a imoralidade e a incoerência das mesmas, passando pela acusação de se tratar tão somente de tradução quase literal de um estudo apresentado à Sociedade de Medicina Legal de Paris, para resolver o problema do aborto criminoso na França. ${ }^{3}$

Um dos pontos a gerar uma acirrada discussão foi a questão da quebra do sigilo médico. Argumentava-se que a notificação compulsória dos casos de aborto criava, na verdade, um gravíssimo problema de deontologia. Poderia o médico, depositário da confiança da doente, quebrar o segredo profissional? 
A defesa apaixonada do projeto por seus signatários não o impediu, no entanto, de ser torpedeado. Fernando de Magalhães fazia duras críticas aos colegas que não concordavam com as propostas de mudanças na lei punitiva do aborto criminoso. Comparando a obrigação do médico de notificar doenças como a tuberculose ou a varíola com a notificação do aborto, ele acusava aqueles contrários a essa medida de sentimentais. Esse sentimentalismo, segundo ele, permitiria que se atropelasse o direito à vida do qual era dotado o embrião. Suas críticas dirigiam-se, sobretudo, a Miguel Couto, seu ferrenho opositor. Este último saiu em defesa da família que, segundo dizia, teria sua intimidade devassada quando uma pessoa do sexo feminino sofresse um aborto e um médico qualquer tivesse de examiná-la para comprovar se era espontâneo ou criminoso. Autointitulando-se um rebelde contra essa possível lei, Miguel Couto encerrou sua fala afirmando preferir "que passem milhares de casos de aborto sem punição, do que seja apontada como capaz disso uma só mulher inocente" (Academia Nacional de Medicina, 1920).

Apesar do empenho do grupo que propunha as modificações na legislação antiaborto, nada foi conseguido. O debate, entretanto, continuaria, adentrando os anos 1930, mas, a partir de então, sob outra conjuntura e com novas implicações.

\section{As alternativas a uma gravidez não desejada}

Antes da segunda metade do século XIX, o aborto por intervenção instrumental não era praticado. A própria mulher ou uma abortadora intervinha no nível da vagina já no fim da gravidez, com o feto já grande e fácil de ser tocado. Esse tipo de operação era, no entanto, incomum, pois que se desconhecia a anatomia do útero e o que se passava em seu interior. A ignorância das parteiras em relação aos mecanismos do trabalho de parto inscrevia-se no desconhecimento geral pela cultura popular, de tudo que se relacionasse ao interior do corpo e a seu funcionamento. Mesmo para os médicos, o aborto instrumental era algo complicado, pois o risco de infecção era sempre uma ameaça (Shorter, 1984, p.180).

Mas caso a gravidez não fosse desejada, que alternativas restariam às mulheres? Sabe-se que, para uma mulher solteira do século XIX e das primeiras décadas do século XX, a gravidez era uma verdadeira catástrofe. Uma vez descoberta, a humilhação e o opróbio a que ficaria exposta, além do estigma que lhe seria infligido, transformariam sua vida em um pesado fardo. Mesmo para uma mulher casada e pobre, com prole numerosa, cansada de sucessivas gestações, a vinda de uma criança indesejada poderia ser concebida como um verdadeiro calvário. Pôr fim a essa situação era antes de tudo um ato desesperado.

Antes que o aborto instrumental entrasse em cena, o que essas mulheres podiam fazer? As teses médicas procuraram mostrar alguns expedientes aos quais as mulheres recorriam para se livrar de uma gravidez inoportuna. Geralmente, começavam por utilizar meios reputados na cultura popular e que poderiam ser empregados sem a ajuda de ninguém. Entre eles figurava o uso das sangrias, sanguessugas, banhos de assento, marchas forçadas, quedas, longas caminhadas, compressão do ventre, massagens etc. Alguns deles poderiam efetivamente agir, como as quedas e as massagens no ventre, a maioria, no entanto, não exercia qualquer efeito nefasto sobre a evolução da gravidez (Costa Júnior, 1911, p.83). 
O passo seguinte era a ingestão de chás e decocções de certos tipos de ervas ou mesmo de substâncias químicas. A cila, a salsaparrilha, o gaiaco, a melissa, o açafrão, a camomila e a artemísia eram algumas das comumente utilizadas (Mattos, 1923, p.24). Algumas dessas substâncias tinham certa ação direta sobre o útero, como o teixo, a sabina, o zimbro, a tuia, a atanásia, a arruda e o centeio-espigado. Produziam intoxicação ou envenenamento que poderia levar a gestante a abortar. Dentre as substâncias químicas empregadas, destacavam-se venenos gerais como arsênico, fósforo, antimônio, mercúrio, chumbo, sulfureto de carbono, iodeto de potássio, sulfato de quinina, clorofórmio, cantáridas, permanganato de potássio, veratrina e pilocarpina (Rizzo, 1925, p.29).

As novas técnicas médicas para o aborto instrumental surgidas na primeira metade do século XIX conferiram às mulheres os meios mais eficazes de controlar sua fecundidade. A primeira delas foi o emprego de um catéter no qual se inseria um fio de ferro pontiagudo. Destinado a provocar o parto prematuro, esse procedimento transformou-se por volta de 1850 em uma técnica médica corrente. Consistia em perfurar a bolsa do líquido amniótico, o que servia para deslanchar o trabalho de parto, sendo imediatamente adotada pelos abortadores. A verdadeira revolução do aborto começou, entretanto, com a descoberta da vulcanização da borracha por Charles Goodyear, em 1839. A partir de 1850, o surgimento dos catéteres feitos dessa matéria suprimia a necessidade dos abortadores utilizarem um objeto pontiagudo, com todos os riscos de perfuração do útero que tal procedimento comportava (Shorter, 1984, p.187).

Na segunda metade do século XIX, disseminou-se o procedimento que consistia em injetar um líquido no útero, em virtude do princípio de que mesmo no início de gravidez é possível provocar contrações por irritação de suas paredes. A água era injetada com a ajuda de uma seringa de modo que a irritação mecânica provocasse finalmente o aborto. Já no início do século XIX, surgiu uma grande diversidade de seringas em metal ou vidro, cujo emprego visando deslanchar o trabalho de parto era feito por médicos. Entretanto, sua difusão exigia a borracha, uma vez que as de cobre ou estanho eram muito caras. Essa técnica também foi difundida e não tardou a ser adotada pelos abortadores e até pelas próprias mulheres que executavam o procedimento por sua própria conta e risco (Shorter, 1984, p.187).

Essas técnicas, surgidas na Europa no século XIX, chegaram sem demora ao Rio de Janeiro. Os médicos relatavam a sua utilização pelos abortadores que atuavam na cidade. Descreviam ainda uma infinidade de manobras abortivas diretas com a introdução no útero - para se obter o despedaçamento e a punção das membranas - de agulhas de tricô, hastes de madeira, penas de ganso, palitos, grampos, sondas etc. Em grande número de casos, esses instrumentos perfuravam a parede uterina causando graves danos à saúde da mulher e, não raro, a morte. Nas autópsias, verificava-se constantemente a presença de fragmentos de hastes ou então sinais de sua passagem por ali (Costa Júnior, 1911, p.87).

Era fácil para uma mulher que não desejasse uma gravidez livrar-se dela? Os médicos que escreveram sobre o tema do aborto afirmavam que sim, sendo unânimes em demonstrar o quanto era simples para as mulheres daquela época o acesso a medicamentos e pessoas que pudessem ajudá-las a alcançar o seu intento. Já em 1845, eles propunham restringir a liberdade comercial dos boticários e droguistas que vendiam livremente substâncias que 
gozavam da fama de abortivas. Sugeriam também que se vedasse aos barbeiros o direito de realizar sangrias sem ordem expressa de um médico (Reis, 1845, p.10).

Com a evolução das técnicas médicas de interrupção da gravidez e da indução do parto, e sua divulgação, a pretensa facilidade com que uma mulher tinha acesso ao aborto, segundo os médicos, ficava ainda mais patente. Um deles observava que a prática do aborto criminoso se alastrava com velocidade espantosa pelo Brasil, desde a capital da República até a mais humilde vila, "desde os indivíduos mais ricos até os mais pobres, e desde os mais finos aristocratas aos burgueses mais simples" (Barbosa, 1911, p.97). E concluindo sua alocução, Barbosa (p.97) acrescentava: "Aqui entre nós, tal qual como se estivéssemos em um país onde só impere o malthusianismo, curandeiros de toda casta, farmacêuticos audaciosos, parteiras indignas e médicos desonestos já se entregaram e se entregam mediante qualquer soma pecuniária ao triste e baixo e execrando papel de cínicos abortistas".

Outro, para realçar a relativa facilidade com que uma mulher se poderia livrar de uma gravidez incômoda, alegava que quem vivia nos meios médicos do Rio de Janeiro poderia assegurar "a frequência desse fato criminoso, nem só porque amiúde o constata, como pelas conversas, até mesmo pelos anúncios de curiosas, parteiras, curandeiros e até de médicos!" (Mattos, 1923, p.12).

Os anúncios feitos pelos jornais de pessoas que ofereciam seus serviços foram, aliás, motivo de irritação profunda do médico Antonio Fernandes da Costa Júnior. Mesmo não declarando expressamente a prática do aborto, esses anunciantes deixavam entrever nas entrelinhas, segundo ele, o seu mister. De fato, esse tipo de anúncio era bastante comum na imprensa diária. Também em exaltado debate na Academia Nacional de Medicina, o doutor Nascimento Silva indignava-se com os anúncios que faziam propaganda abortiva nos jornais. Frases como: "evita a gravidez nos casos indicados, fazendo aparecer o incômodo sem provocar hemorragia", "tratamento do útero e suspensões", "faz aparecer o incômodo por processo científico e sem dor, sem o menor perigo para a saúde: trabalhos garantidos", "evita gravidez por indicação científica, sem prejudicar o organismo" eram citadas como prova da audácia dos abortistas (Academia Nacional de Medicina, 1918b).

\section{A legislação sobre o aborto, sua punição e profilaxia}

Segundo o Código Criminal do Império do Brasil de 1830, em seu artigo 199, punia-se com a pena de prisão com trabalhos de um a cinco anos a pessoa que ocasionasse aborto por "qualquer meio empregado interior ou exteriormente com consentimento da mulher pejada" (Brasil, 16 dez. 1830, p.33).

Caso o crime fosse cometido sem o consentimento da mulher, as penas seriam dobradas. O artigo 200 do mesmo Código punia com pena de prisão com trabalhos, por dois anos, a pessoa que com conhecimento de causa fornecesse drogas ou quaisquer outros meios para produzir o aborto, ainda que este não se verificasse. Se o ato fosse cometido por médico, boticário, cirurgião ou praticante de tais artes, as penas seriam dobradas.

Em sua tese sobre o aborto, o médico João Gomes dos Reis $(1845$, p.5) comentava a legislação a respeito e demonstrava sua insatisfação em relação à distribuição das penas. 
Para ele, uma das faltas cometidas por aqueles que haviam elaborado o Código dizia respeito à mulher grávida: "quiséramos que as mães também fossem punidas, e que se estabelecessem penas graduadas, de maneira que um juiz ilustrado e consciencioso pudesse bem repartir a justiça, segundo esta ou aquela circunstância, de que o delito fosse revestido".

O Código Penal de 1890 (Brasil, 11 out. 1890) promulgado, portanto, já sob a República, veio, por fim, contemplar aqueles que ansiavam por uma punição das mulheres que praticavam o aborto. Em seu artigo 30, o novo Código tratava-o como crime contra a segurança da pessoa e da vida. As penas para os abortadores variavam de seis meses a um ano. Se, em consequência do ato, sobreviesse a morte da mulher, a prisão celular seria de seis a 24 anos. Caso o aborto fosse provocado por médicos ou parteira habilitada, a penalidade seria igual, com o agravante da privação do exercício da profissão por tempo igual ao da condenação.

Pelo artigo 301, a pessoa que provocasse o aborto com a anuência e o acordo da gestante estaria sujeita à pena de prisão celular de um a cinco anos. Em igual pena incorreria a gestante que conseguisse abortar voluntariamente, mas ela lhe seria reduzida da terça parte se o crime fosse cometido para ocultar a desonra.

O artigo 302 tratava do aborto legal ou necessário para salvar a gestante de morte inevitável. Mesmo nesses casos, se o médico ou a parteira ocasionasse a morte por imperícia ou negligência sofreria pena de prisão celular variável de dois meses a dois anos, bem como a privação do exercício da profissão pelo mesmo tempo da condenação.

A diminuição da pena concedida às mulheres que abortavam para esconder a desonra merece algumas considerações. Procurava-se justificá-la sob a alegação de que a sociedade já punia de forma bastante dura a mulher que engravidava fora dos parâmetros sociais considerados ideais para se gestar um novo ser, ou seja, fora do casamento. Nesse sentido, um médico expressou-se de forma eloquente: "Na verdade, se a sociedade condena a mulher que teve a infelicidade, em horas em que a consciência vacila, de lançar-se no abismo, como pode a mesma sociedade fazer passível de pena aquela que para não ser o ludibrio, o poste de apodos de todos os lados, procura, embora por meios menos dignos, ou antes, com outro delito, furtar-se à publicidade do primeiro" (Câmara, 1899, p.16).

Entretanto, é necessário atentar para o caminho cheio de percalços entre as leis que criminalizavam o aborto e sua real punição. O primeiro problema surgia justamente em relação à efetiva constatação da existência da gravidez. A mulher acusada de ter provocado o aborto estava verdadeiramente grávida ou se tratava apenas de um atraso menstrual? Em seguida, questionava-se se o aborto fora espontâneo ou provocado. Se provocado, qual o meio utilizado? O aborto era realmente necessário para salvar a gestante da morte? Essas eram algumas das perguntas às quais os médicos legistas deveriam responder para que se pudesse constatar a prática do aborto criminoso. Excetuando-se os casos dramáticos de graves infecções, perfuração do útero, ou morte, em que ficava claramente estabelecida a intenção de abortar, a medicina da época tinha extrema dificuldade em responder com absoluta certeza a essas perguntas. O aborto era, portanto, de difícil comprovação (Ardaillon, 1994, p.213-249). ${ }^{4}$

Os médicos queixavam-se frequentemente disto. Alegavam que as novas técnicas médicas de interrupção da gravidez haviam sido rapidamente apropriadas pelos abortistas que, por 
sua vez, realizavam intervenções que praticamente não deixavam vestígios: "além da vulgarização das noções elementares de assepsia que concorrem para diminuir a mortalidade pelo aborto, mesmo quando ele é praticado clandestinamente, as inspirações recebidas pelos progressos realizados em ginecologia, vulgarizadas em brochuras, livros acessíveis a todos, tornam a prova médica de que um aborto foi provocado senão impossível pelo menos extraordinariamente difícil" (Mattos, 1923, p.115).

Diante disso, reiterava-se a necessidade de mudanças nas leis que criminalizavam o aborto, visando barrar a generalização da impunidade. Imbuídos do papel de guardiões da moralidade pública, os médicos procuravam mobilizar a sociedade para os graves problemas ocasionados por sua prática, propondo medidas que concorressem para refreála. Ainda em 1911, o doutor Antonio Fernandes da Costa Júnior propunha uma série de medidas que, segundo ele, concorreriam para "sofrear esse crime". A primeira delas consistia na alteração da interpretação do segredo profissional. Muitos profissionais não denunciavam o aborto criminoso por considerarem que estariam lesando o sigilo médico, daí porque se deveria aplicar, segundo ele, as mesmas disposições existentes para os casos de conhecimento de moléstias infecciosas (peste, varíola) para que não subsistissem dúvidas (Costa Júnior, 1911, p.115).

Outra medida proposta era a regularização e fiscalização das funções e atribuições das parteiras. Para Costa Júnior (1911, p.115), as parteiras diplomadas ou não, eram "o maior fator da prática do aborto criminoso". Além dos anúncios nos jornais nos quais ofereciam suas atividades ilegais, elas não se limitavam às suas atribuições e invadiam aquelas próprias aos médicos ao realizar procedimentos ginecológicos. Deveriam, então, ser fiscalizadas para que se limitassem às suas funções e, uma vez envolvidas em processos criminais, a simples presença em suas casas de instrumentos cirúrgicos impróprios ao seu oficio já seria prova inconteste de sua responsabilidade criminal.

$\mathrm{O}$ aumento da penalidade também era proposto como forma de amedrontar aqueles que pretendessem se envolver com esse tipo de crime. Finalmente, o médico sugeria também o segredo do inquérito policial, pois que a divulgação de um fato daquela natureza era invariavelmente acompanhada de comentários desagradáveis, o que fazia com que muitos profissionais se apiedassem dos criminosos e não comunicassem as ocorrências à polícia.

Em 1918, as ideias de Costa Júnior foram retomadas por um grupo de médicos proeminentes - capitaneados por Nascimento Silva - e incluídas em um projeto mais amplo, apresentado para debate na Academia Nacional de Medicina, ao qual já nos referimos.

Em 1923, em sua tese, o médico Archimino Martins de Mattos retomou o assunto, clamando pelos direitos do embrião, amparando-se em estudos embriológicos e de juristas como Clóvis Bevilacqua e Teixeira de Freitas. Declarando ser o mesmo uma pessoa, propunha a inclusão do crime de aborto no crime de homicídio. Reconhecendo-se, portanto, o direito à vida do novo ser, em seu favor deveria se estender também a assistência do Estado, não o deixando "aos azares das vontades criminosas".

A intervenção do Estado não deveria, entretanto, parar por aí: "um serviço profilático, amplamente divulgado, deveria ser tentado, já ensinando-se nas escolas o culto à maternidade, já nas associações científicas e religiosas, fazendo-se larga propaganda contra o crime e em favor da criança; já criando-se hospitais em que as gestantes possam se abrigar, 
confortavelmente, e sem vexames, já organizando-se uma vasta assistência à criança, como sejam asilos, creches, gotas de leite etc." (Mattos, 1923, p.48).

Além de manter esses serviços, o Estado deveria também, em sua opinião, incentivar a iniciativa particular através de medidas inteligentes. As dotações de entidades como a Rockefeller, reiterava, já haviam "prestado relevantes serviços ao mundo". Por que, então, não copiar esse exemplo, estabelecendo uma grande associação de proteção e amparo às mães e aos filhos? (Mattos, 1923, p.49).

Opinião semelhante tinha o doutor Mileto Rizzo (1925), para quem o parto era uma "função natural", e o embrião um ser a quem a sociedade devia proteção. Uma vez que as leis eram "abandonadas até por aqueles que além de respeitá-las deveriam fazê-las cumprir estritamente" (p.56), restava aos médicos, segundo pensava, a "campanha benemérita que é a profilaxia do aborto; a profilaxia moral, a profilaxia repressiva" (p.56). Era necessário educar a futura mãe de modo a que sentisse orgulho com o "sublime sacrifício da maternidade", vendo nela não apenas um "encargo nobre", mas também um "dever sagrado". Esse serviço profilático deveria ser executado, pregando-se nas escolas e nas associações científicas ou religiosas o culto à maternidade, abrindo-se "tremenda campanha contra o aborto criminoso" (p.56).

A questão do aborto mobilizou sobremaneira a consciência médica, desdobrando-se por um lado em luta pela afirmação profissional desse grupo diante dos demais que pudessem ameaçar sua hegemonia e, por outro, em luta pelo controle da sexualidade feminina.

A acusação peremptória de que parteiras, curandeiras, vendedores de ervas medicinais e boticários praticavam o aborto criminoso deixava entrever a preocupação dos médicos em obter para si o monopólio dos atos ligados à interrupção da gravidez. A eles deveria caber a decisão de quando e por que razão uma mulher poderia abortar. Ao chamar exclusivamente para si tal decisão, os médicos buscavam reafirmar seu poder de classe e de gênero.

À campanha antiabortiva movida pelos médicos nas três décadas do século XX mesclavase também a luta anticontraceptiva. As ideias neomalthusianas que propunham uma diminuição do número de filhos por casal lhes pareciam ameaçadoras. O leito conjugal 'conspurcado' pela 'fraude' do coitus interruptus, do preservativo, do tampão vaginal ou da esterilização era um sinal de que a 'mulher honesta', a mãe de família, não estava cumprindo a sua função 'natural'.

A possibilidade de existência do prazer feminino, fora da prostituição, era perturbadora. Juntava-se a isso a possibilidade do adultério feminino. Liberada do risco de engravidar, quem garantiria que a mulher casada não desonrasse o nome de seu marido?

Mesmo as poucas vozes discordantes do tom geral do período, que chegaram a propugnar a limitação do número de filhos por casal, admitiram, quando muito, a utilização da abstinência sexual e do preservativo. Este último dependia da concordância masculina, obviamente, e devido aos limites para sua aquisição fora da prescrição e do controle médico, tornou-se um método fora do alcance da maioria. A abstinência, por sua vez, ficava na dependência sobretudo do autocontrole do homem, que, uma vez rompido, poderia leválo a requisitar a relação sexual mesmo com o uso da violência, amparando-se na legislação vigente que não previa - como até hoje ainda não prevê - a existência de estupro dentro do casamento (Figueira, 1998). 
Mesmo como objetos de estrito controle e dominação, as mulheres buscaram saídas próprias para o dilema de assumir ou não a maternidade. O recurso ao aborto, mesmo sob o risco da própria vida, e ao infanticídio, com todo seu cortejo de execração e penalização, pode ser entendido como modos de ultrapassar as formas de domínio exercidas sobre o corpo reprodutor das mulheres. ${ }^{5} \mathrm{~A}$ busca da autonomia sobre o processo de reprodução pode e deve ser pensada como extrema subversão, abrindo perspectivas de mudanças no status social da mulher e apontando no sentido da instituição de uma nova ordem de gênero.

O que restava às mulheres desse período? Uma prole numerosa e as consequências disso - desgaste físico, subalternidade, empobrecimento - ou o aborto, realizado em condições de ilegalidade e de risco para a vida. Esse dilema por elas vivenciado, estreitamente ligado à sua capacidade reprodutiva, ainda permanece atual. Sua resolução depende da ultrapassagem da concepção do corpo feminino como objeto da reprodução. Já não é de hoje que os direitos e a saúde reprodutiva são controlados pelas próprias mulheres.

\section{NOTAS}

${ }^{1}$ Desde o início do século XIX, o equilíbrio demográfico na França fora rompido. A tomada de consciência em relação a esse fenômeno efetuou-se por volta de 1875. Daí para frente, a contracepção, que começava a se desenvolver - o aborto, o preservativo e o diafragma vaginal -, passou a ser duramente combatida.

${ }^{2} \mathrm{O}$ Correio da Manhã deu ampla cobertura ao fato.

${ }^{3}$ Um bom momento desse debate aparece em Academia Nacional de Medicina (1918a, 1918b).

${ }^{4}$ Mesmo na atualidade, o crime de aborto é de comprovação extremamente complicada.

${ }^{5}$ Os próprios médicos alertavam para o fato de que o infanticídio e o aborto criminoso cresceram assustadoramente durante esse período. Sobre essa questão, ver Soihet, 1989.

\section{REFERÊNCIAS}

ABORTO...

Aborto de alto risco é terceira causa de morte materna no país. O Globo, Rio de Janeiro, p.3. 20 maio 2007.

ACADEMIA NACIONAL DE MEDICINA. Boletim da Academia Nacional de Medicina, Rio de Janeiro, ano 91, n.17. Sessão de 5 de agosto de 1920. 1920

ACADEMIA NACIONAL DE MEDICINA. Boletim da Academia Nacional de Medicina, Rio de Janeiro, ano 89, n.16. Sessão de 25 de julho de 1918. 1918a.

ACADEMIA NACIONAL DE MEDICINA. Boletim da Academia Nacional de Medicina, Rio de Janeiro, ano 89, n.4. Sessão de 25 de abril de 1918. 1918b.

ARDAILLON, Danielle. O aborto no Judiciário: uma lei que justiça a vítima. In: Bruschini, Cristina; Sorj, Bila (Org.). Novos olhares: mulheres e relações de gênero no Brasil. São Paulo: Fundação Carlos Chagas. p.213-249. 1994.
BARBOSA, Luiz Gonzaga Vianna.

Malthus no Brasil. Tese - Faculdade de Medicina do Rio de Janeiro, Rio de Janeiro. 1911.

BRASIL.

Decreto n. 847, de 11 de outubro de 1890. Promulga o Código Penal. Disponível em: http://www6.senado.gov.br/legislacao/ ListaPublicacoes.action?id=66049. Acesso em: 4 set. 2012 . 11 out. 1890 .

BRASIL.

Lei de 16 de dezembro de 1830. Manda executar o Código Criminal. Disponível em: http://www.planalto.gov.br/ccivil_03/Leis/LIM/ LIM-16-12-1830.htm. Acesso em: 4 set. 2012. 16 dez. 1830 .

CÂMARA, José de Paula.

Do aborto criminoso. Tese - Faculdade de Medicina do Rio de Janeiro, Rio de Janeiro. 1899.

COSTA, João.

A restrição da natalidade. Tese - Faculdade de Medicina do Rio de Janeiro, Rio de Janeiro. 1913. 
COSTA JÚNIOR, Antônio Fernandes da. O aborto criminoso no Rio de Janeiro. Tese Faculdade de Medicina do Rio de Janeiro, Rio de Janeiro. 1911.

FIGUEIRA, Luiz Eduardo.

Violência sexual legitimada. Discursos Sediciosos, Rio de Janeiro, ano 3, n.5 e 6, p. 19-35. 1998.

GLEYSES, Chantal.

La femme coupable. Petite histoire de l'épouse adultère au XIXeme siècle. Paris: Éditions Imago. 1994.

LIGIERO, Manoel.

Algumas considerações sobre o neomalthusianismo como fator eugênico. Tese - Faculdade de Medicina do Rio de Janeiro, Rio de Janeiro. 1930.

MARQUES, Vera Regina Beltrão.

A medicalização da raça: médicos, educadores e o discurso eugênico. Campinas: Editora da Unicamp. 1994.

MATTOS, Archimino Martins de. Aborto criminoso. Tese - Faculdade de Medicina do Rio de Janeiro, Rio de Janeiro. 1923.

MELLO, José Rodrigues da Graça.

Da justificação dos meios anticoncepcionais temporários na profilaxia moral e social. Tese Faculdade de Medicina do Rio de Janeiro, Rio de Janeiro. 1911.

MORAIS, Evaristo de.

Os inimigos do povoamento esterilizadores e abortistas. Correio da Manhã, Rio de Janeiro, p. 2. 25 maio 1911.

MOTT, Maria Lucia de Barros.

Parteiras no século XIX: Madame Durocher e sua época. In: Costa, Albertina de Oliveira;
Bruschini, Cristina (Org.). Entre a virtude e o pecado. Rio de Janeiro: Rosa dos Tempos; São Paulo: Fundação Carlos Chagas. p. 37-56. 1992.

REIS, João Gomes dos.

Dissertação médico-legal sobre o aborto precedida de algumas considerações acerca dos motivos que em geral levam as mulheres a provocá-lo e meios de $o$ prevenir. Tese - Faculdade de Medicina do Rio de Janeiro, Rio de Janeiro. 1845.

RIZZO, Mileto.

Considerações acerca do aborto criminoso. Tese Faculdade de Medicina do Rio de Janeiro, Rio de Janeiro. 1925.

SHORTER, Edward.

Le corps des femmes. Paris: Seuil. 1984.

SILVEIRA, Alfredo Balthazar da.

O aborto criminoso, suas causas, seus remédios. Conferência feita no Instituto da Ordem dos Advogados Brasileiros. Rio de Janeiro: Francisco Alves. 1918.

SOIHET, Rachel.

Condição feminina e formas de violência: mulheres pobres e ordem urbana, 1890-1920. Rio de Janeiro: Forense Universitária. 1989.

TABET, Paola.

Fertilité naturelle, reproduction forcée. In: Mathieu, Nicole-Claude (Dir.). L'arraisonnement des femmes: essais en anthropologie des sexes. Paris: Éditions de l'EHESS. p.61-132. 1985.

VILHENA, Mario Alcântara de.

Da continência e seu fator eugênico. Tese Faculdade de Medicina do Rio de Janeiro, Rio de Janeiro. 1919.

\section{$\rightarrow \rightarrow \rightarrow<<$}

